\title{
MAKNA INOVASI DALAM PANDANGAN PENGURUS KOPERASI SE-BANDUNG RAYA PADA ERA REVOLUSI INDUSTRI 4.0
}

\author{
Khaerul Syobar \\ STKIP Pasudan, Cimahi \\ Email: khaerul06@gmail.com
}

\begin{abstract}
The purpose of this research is to find out what the meaning of innovation is in the view of cooperative administrators throughout Bandung Raya, especially in the era of the industrial revolution 4.0. This arises from the existence of increasingly fierce competition in innovating both regionally, nationally and internationally in the era of the industrial revolution 4.0. The research approach used is with qualitative research methods. Retrieval of data through interviews, observation and documentation. The results show that the meaning of innovation in the view of cooperative administrators in Bandung Raya, especially in the era of the industrial revolution 4.0, is threefold, namely: (1) innovation in the view of cooperative administrators throughout Bandung Raya as increasing productivity, (2) innovation in the view of cooperative administrators -Bandung Raya as customer needs, and (3) innovation in the view of cooperative administrators throughout Bandung Raya as a way to improve performance. The conclusion of this study is that innovation in the era of the industrial revolution 4.0 for cooperative managers throughout Bandung Raya is a necessity in order to maintain the existence of cooperatives in the era of the industrial revolution 4.0
\end{abstract}

Keywords: meaning, innovation, bandung raya, industrial revolution 4.0.

\begin{abstract}
Abstrak
Tujuan penelitian ini ialah untuk mengetahui bagaimana makna inovasi dalam pandangan pengurus koperasi se-Bandung Raya khususnya pada era revolusi industri 4.0. Hal ini muncul dari adanya persaingan yang semakin ketat dalam berinovasi baik regional, nasional, maupun internasional di era revolusi industri
\end{abstract}


4.0. Pendekatan penelitian yang digunakan adalah studi kualitatif jenis fenomenologi. Pengambilan data melalui wawancara, observasi dan dokumentasi. Hasil penelitian menunjukkan bahwa makna inovasi dalam pandangan pengurus koperasi se-Bandung Raya khususnya pada era revolusi industri 4.0 ada tiga, yaitu : (1) inovasi dalam pandangan pengurus koperasi se-Bandung Raya sebagai meningkatkan produktivitas, (2) inovasi dalam pandangan pengurus koperasi seBandung Raya sebagai kebutuhan pelanggan, dan (3) inovasi dalam pandangan pengurus koperasi se-Bandung Raya sebagai cara dalam meningkatkan kinerja. Kesimpulan penelitian ini adalah inovasi pada era revolusi industri 4.0 bagi pengurus koperasi se-Bandung Raya merupakan keniscayaa dalam rangka mempertahankan eksistensi koperasi di era revolusi industri 4.0.

\section{Kata kunci: makna, inovasi, se-bandung raya, revolusi industri 4.0.}

\section{PENDAHULUAN}

Era revolusi indutri telah memberikan peluang perubahan pada setiap aspek kehidupan manusia terlihat dari kenyataan saat ini bahwa perubahan karena revolusi indutri terjadi dengan pesat. Dalam hal ini Mohajan (2019) menyatakan bahwa revolusi industri telah membawa pembaharuan untuk pertumbuhan ekonomi global, peningkatan produksi dan konsumsi. Mohajan juga menjelaskan bahwa sistem komunikasi transportasi telah diperbaiki dan sistem keuangan ditingkatkan untuk menjalankan industri serta bisnis. Maka dari itu, wajar saja jika dalam pusaran revolusi indutri, berbagai perubahan secara perlahan namun pasti terjadi.

Berdasarkan situasi era revolusi industri, terdapat dua hal yang dapat di pahami yaitu menjadikan solusi dan tantangan dalam kehidupan manusia. Pada sisi lainnya, Era revolusi indutri menjadikan koperasi menjadi bagian yang strategis untuk UMKM dan perkembangan kota dengan terciptanya skala ekonomi baru dengan dasar filosopis kerjasamanya. Rysz \& Mazurek-Matuszewska (2015) menyatakan bahwa persoalan konsep pembangunan secara optimal perlu ditetapkan sebagai aktivitas manusia mana yang dianggap sebagai pengembangan ruang sadar dan terencana. Maka pada era revolusi indutri, jika konsep pembangunan dan pengelolaan kota ditinjau ulang, terdapat berbagai komponen dalam pembangunan yang berperan dalam menunjang kerjasama namun juga menimbulkan persaingan.

Branch (1995) berpendapat jika kota memiliki berbagai unsur yang terdiri dari komponen fisik, sosial dan ekonomi. Maka dalam pembangunan dalam suatu kota, unsur-unsur tersebut perlu ditinjau ulang dalam rangka mengetahui proses dan indikator bagaiman pembangunan dalam kota tersebut berjalan. Sejalan 
dengan hal tersebut, Houston, Hillier, MacCallum, Steele, \& Byrne (2017) menyatakan banyak teori perencanaan telah didukung oleh eksepsi ontologis manusia. Namun, perencanaan kota tidak duduk di luar realitas eko-sosial yang ikut menghasilkan Antroposen. Oleh karena itu, perencana kota perlu memperhatikan konsep keberlanjutan yang dapat membentuk, mengarah dan menciptakan peradaban yang sesuai dengan jati diri suatu bangsa.

Transisi berbagai unsur dalam pembangunan dan pengelolaan kota telah meningkatkan efisien berbagai komponen fenomen revolusi industri. Pada situasi ini, Kehadiran koperasi tidak tertanggalkan dalam mendukung inovasi yang menjadi keniscayaan di era revolusi industri ini. Bello Dogarawa (2005) menyatakan bahwa selama lebih dari 160 tahun koperasi menjadi cara yang efektif bagi masyarakat untuk menggunakan kendali atas ekonomi mereka karena penting dalam memfasilitasi penciptaan lapangan kerja, pertumbuhan ekonomi dan pembangunan sosial. Maka dari itu, keberadaan koperasi perlu menjadi perhatian dalam pertumbuhan ekonomi dan pembangunan sosial.

Kehadiran koperasi dan inovasi dalam kebangkitan ekonomi pada konteks pembangunan menjad salah satu hal menarik. Hal ini karena koperasi menjadi badan usaha yang dapat membebaskan anggotanya dalam hal kesulitan ekonomi. Pada tahun 1967, di Indonesia, terbit Undang-undang Nomor 12 tahun 1967 tentang pokok-pokok perkoperasian yang menjadi landasan bagi pengembangan perekonomian rakyat melalui koperasi. Pada pasal 3 dikemukakan pengertian koperasi yang menyatakan "Koperasi Indonesia adalah organisasi ekonomi rakyat yang berwatak sosial beranggotakan orang-orang atau badan-badan hukum. Koperasi yang merupakan tata susunan ekonomi sebagai usaha bersama berdasar atas azas kekeluargaan". Berdasarkan hal ini maka, terdapat peluang dalam hal inovasi melalui koperasi yang dapat menjadi alternatif dalam persoalan ekonomi.

Pada konteks Indonesia, terdapat berbagai fenomena mengenai kehadiran koperasi dalam masyarakat dan perkambangannya. Berikut adalah data yang menunjukan kehadiran koperasi dan masalahnya dalam konteks Indonesia.

1. Terdapat faktor penghambat koperasi di Indonesia yaitu sisi kelembagaan dan sisi bidang usaha yang menjadi penghambat koperasi di Indonesia (Sitepu \& Hasyim, 2018)

2. Terdapat pola dalam perkembangan koperasi yaitu pertama koperasi menjadi dalam instrument penyelesaian persoalan kemiskonan, dan kedua koperasi menjadi tempat dalam pengembangan usaha dalam rangka memperoleh keuntungan (Rahardjo, 2011)

3. Tantangan pengembangan koperasi di Indonesia ialah penegasan koperasi sebagai badan hukum, pembatasan simpan pinjam bagi anggota, penempatan unit simpan pinjam yang berubah menjadi KSP dan menjadi badan hukum tersendiri yang menjadi syara dalam LPS KSP, ketatnya nomenklatur koperasi 
dalam Undang-Undang, munculnya istilah setoran pokok dan sertifikat modal koperas sebagai pengganti istilah simpanan pokok, simpanan wajib dan simpanan sukarel menimbulakan kebingunan, posisi pengawas lebih kuat dari pada pengurus (Raharja, 2013)

4. Koperasi di Indonesia mengalami pasang surut, pada masa penjajahan koperasi hanya sebatas pada peran koperasi sebagai pelaku usaha, pada masa kemerdekaan koperasi ditujuan dalam rangka memeratakan kesejahteraan rakyat, pada masa reformasi koperasi semakin bercitra buruk karena dominan seperti perusahaan yang hanya mengejar pada keuntungan (Zain, 2014)

5. Perkembangan koperasi di Indonesia pada tahun 200-an mengarah pada perkembangan koperasi faham ekonomi politik heterodoks (Maulana, 2016)

Berdasarkan berbagai fenomena mengenai koperasi yang telah di sajikan, tersirat menunjukan terjadinya "masalah" pada koperasi, khususnya di Indonesia. Berhubungan dengan situasi tersebut, Nel \& Stevenson (2014) mengungkapkan jika peran kunci dalam mendorong kesejahteraan ekonomi ialah kurangnya dukungan negara. Pada situasi koperasi di Indonesia, sejatinya koperasi merupakan bagian dari roda ekonomi di Indonesia maka kehadiran koperasi seharusnya dapat menjadi wahana dalam memfasilitasi perbaikan ekonomi dan kesejahteraan masyarakat Indonesia.

Perpaduan berbagai aspek inovasi pada gilirannya dapat membentuk inovasi. Boer (2001) membedakan inovasi dalam tiga jenis yaitu inovasi produk, inovasi proses, dan inovasi organisasi. Pada umumnya, inovasi muncul berbarengan dengan kreativitas dengan mengoptimalkan sumber daya yang ada. Boer (2001) juga menyatakan bahwa saat ini, inovasi adalah salah satu faktor terpenting dalam perkembangan ekonomi, produksi, penciptaan berbagai produk dan dalam pengambilan keputusan manajemen. Maka dari itu, inovasi dapat berpengaruh positif dalam berbagai hal.

Sebagai salah satu wilah di Indonesia yang berkambang, Wilayah Bandung Raya terdiri dari Kota Bandung, Kota Cimahi, Kabupaten Bandung dan Kabupaten Bandung Barat mahsyur dengan konsep metropolitan, memiliki dasar pada konsep pembangunan dan pengelolaan pembangunannya. Tim WJP-MDM (2013) membagi keunggulan konsep metropolitan wilayah Bandung Raya yang diklasifikasikan dalam tiga hal yaitu absolut advantage, yang berkaitan keunggulan suatu wilayah, comparative advantage yang berkaitan dengan keunggulan komparatif dan competitive advantage yang berkaitan dengan keunggulan suatu wilayah karena berpengalaman dalam bidang ilmu pengetahuan dan teknologi.

Wilayah Bandung Raya menyadari akan adanya berbagai persoalan dalam berbagai bidang yang terkait dengan perkembangan wilayah tersebut. Dengan 
October , 2020

demikian maka, untuk mewujudkan internalisasi kebermakanaan, kehadiran koperasi di Wilayah Bandung Raya patut menjadi perhatian bersama bilamana kehadiran koperasi dapat menciptakan solusi dalam persoalan ekonomi sehingga akan terwujud kesejahteraan masyarakat itu sendiri. Berikut, adalah kondisi koperasi Se Bandung Raya, mencakup dua kabupaten (Kabupaten Bandung, KBB) dan dua kota (Kota Bandung, Kota Cimahi).

Tabel 1. Kondisi Koperasi se Bandung Raya (2012-2014)

\begin{tabular}{|c|c|c|c|c|c|c|c|c|c|c|}
\hline \multirow{3}{*}{ No } & \multirow{3}{*}{ Kab./Kota } & \multicolumn{9}{|c|}{ Jumlah Koperasi } \\
\hline & & \multicolumn{3}{|c|}{2012} & \multicolumn{3}{|c|}{2013} & \multicolumn{3}{|c|}{2014} \\
\hline & & $\mathbf{T}$ & $\mathbf{A k}$ & TA & $\mathbf{T}$ & $\mathbf{A k}$ & TA & $\mathbf{T}$ & $\mathbf{A k}$ & TA \\
\hline 1 & Kota Bandung & 2452 & 1880 & 572 & 2446 & 1874 & 572 & 2452 & 1880 & 572 \\
\hline 2 & Kab Bandung & 1470 & 766 & 704 & 1477 & 999 & 478 & 1624 & 902 & 722 \\
\hline 3 & KBB & 608 & 327 & 281 & 608 & 327 & 281 & 608 & 327 & 281 \\
\hline 4 & Kota Cimahi & 364 & 226 & 138 & 363 & 225 & 138 & 370 & 233 & 137 \\
\hline \multicolumn{2}{|c|}{$\begin{array}{c}\text { JumlahTotal koperasi } \\
\text { se Bandung Raya }\end{array}$} & 4894 & 3199 & 1695 & 4894 & 3425 & 1469 & 5054 & 3342 & 1712 \\
\hline
\end{tabular}

Sumber : Data diolah dari Diskumkm. Prov. Jabar. 2015.

Ket: $T=$ total; $A k=$ Aktif; dan TA = Tidak Aktif.

Dari uraian yang telah dikemukakan, nampak bahwa koperasi memiliki peran dalam hal inovasi bagi anggotanya. Brat, Martínez, \& Ouchene (2016) menyatakan prioritas inovasi dalam koperasi mencakup fokus pada jenis inovasi tertentu (penemuan kembali, penyuluhan, penyemaian, inovasi terbuka), tinjauan organisasi inovasi dan proses dalam koperasi, berdasarkan pendekatan "Berpikir lokal, bertindak global". Berdasarkan hal tersebut maka terdapat transfer of value inovasi pada koperasi yang dapat mengejawantakan perubahan dalam koperasi sendiri.

Berdasarkan hal tesebut, maka di rasa penting untuk dapat mengetahui bagaimana makna inovasi dalam pandangan pengurus koperasi se-Bandung Raya khususnya pada era revolusi industri 4.0. Hal ini menjadi upaya dalam menginvestigasi dimana hal tersebut dapat menjadi instrumen dalam menghadapi permasalahan yang telah melanda koperasi di Indonesia.

\section{METODE PENELITIAN}

Ruang lingkup penelitian ini adalah makna inovasi dalam pandangan pengurus koperasi se-Bandung Raya khususnya pada era revolusi industri 4.0 maka dalam penelitian ini pendekatan yang digunakan adalah kualitatif dengan didasarkan pada pendapat Moleong (2005) bahwa penelitian kualitatif ialah penelitian berupa kata-kata yang mengungkapkan makna. 
Jenis penelian ini adalah fenomenologi, Penelitian di awali dengan melakukan studi pendahuluan pada Bandung Raya guna mendapatkan keadaan objektif mengenai makna inovasi dalam pandangan pengurus koperasi se-Bandung Raya khususnya pada era revolusi industri 4.0.

Data primer dalam penelitian ini adalah di dapat melalui wawancara pada narasumber secara langsung, Unit analisis adalah pengurus koperasi se Bandung Raya yang telah melaksanakan RAT (Rapat Anggota Tahunan) dan data sekunder merupakan hasil penelitian terdahulu yang termuat dalam laporan ilmiah. Adapun data primer wawancara di dapat dari subjek penelitian berikut ini:

Tabel 2. Adapun Data Primer Wawancara

\begin{tabular}{|l|l|l|l|}
\hline Inisial & \multicolumn{1}{|c|}{ Wilayah koperasi } & \multicolumn{1}{|c|}{ Jabatan } & $\begin{array}{c}\text { Lama bergabung dalam } \\
\text { koperasi }\end{array}$ \\
\hline MFA & Kota Bandung & Pengurus & 3 tahun \\
\hline ABP & Kota Cimahi & Pengurus & 2 tahun \\
\hline PYI & Kabupaten Bandung & Pengurus & 4 tahun \\
\hline MOK & Kabupaten Bandung Barat & Pengurus & 4,5 tahun \\
\hline
\end{tabular}

Analisis data menggunakan Milers dan Huberman yang terdiri dari pengumpulan data, reduksi data, penyajian data dan penarikan kesimpulan (Miles, M.B. and Huberman, 1992). Adapun kebsahan data menggunakan triangulasi.

\section{HASIL DAN PEMBAHASAN}

Berdasarkan hasil penelitian, terdapat makna inovasi dalam pandangan pengurus koperasi se-Bandung Raya khususnya pada era revolusi industri 4.0 yaitu (1) inovasi dalam pandangan pengurus koperasi se-Bandung Raya sebagai meningkatkan produktivitas, (2) inovasi dalam pandangan pengurus koperasi seBandung Raya sebagai kebutuhan pelanggan, dan (3) inovasi dalam pandangan pengurus koperasi se-Bandung Raya sebagai cara dalam meningkatkan kinerja. Secara khusus akna inovasi dalam pandangan pengurus koperasi se-Bandung Raya dapat di gambarkan sebagai berikut:

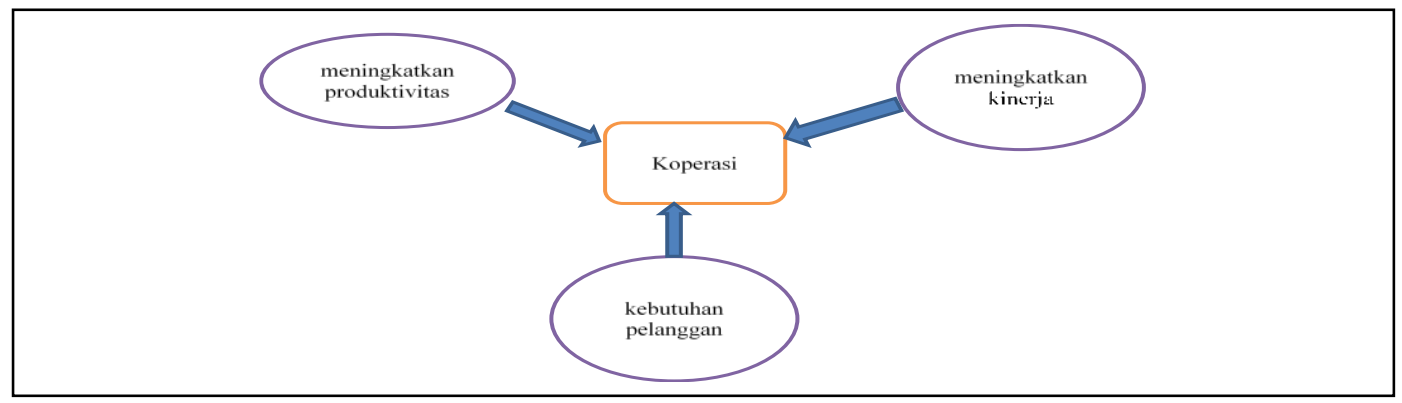

Gambar 1: Inovasi dalam pandangan pengurus koperasi se-Bandung Raya 
October , 2020

Berdasarkan gambar 1 mengenai inovasi dalam pandangan pengurus koperasi seBandung Raya terdapat berbagai faktor yang mempengaruhinya. Pengaruh tersebut memberikan orientasi kognitif mengenai koperasi pada anggota sehingga dapat menyeimbangkan antara pengetahuan anggota koperasi dengan aktivitas dalam koperasi. Hal tersebut tentu saja sesuai dengan pernyataan Cleave \& Arku (2014) yang mengemukakan bahwa dalam kerangka persaingan global, seringkali dikatakan bahwa masyarakat dapat melakukan kerja sama antar yurisdiksi untuk meningkatkan daya saing mereka.

Makna inovasi dalam pandangan pengurus koperasi se-Bandung Raya yang pertama adalah sebagai meningkatkan produktivitas. Skerratt \& Steiner (2013) menyatakan bahwa, ada kebutuhan untuk tetap skeptis terhadap kompleksitas pemberdayaan. Maka dari itu, Sikap individu pada inovasi di koperasi se-Bandung Raya memberikan arah dalam hal berpartisipasi dengan pesaing global. Melalui koperasi sebagai komunitas yang diberdayakan, anggota koperasi secara implisit diarahkan untuk dapat meningkatkan produktivitas. Maka dari itu, meningkatkan produktivitas melalui inovasi menjadi salah satu hal yang dipahami oleah anggota koperasi.

Berdasarkan hasil wawancara dengan narasumber MFA di koperasi wilayah Kota Bandung mengenai pandangan inovasi sebagai meningkatkan produktivitas, di dapat data bahwa pengetahuan dalam meningkatkan produktivitas dalam koperasi mempunyai pandangan yang visioner. Sejalan dengan hal tersebut Hosseini, McElwee, Soltani, \& Smith (2012) menyatakan bahwa di bidang pengolahan dan pengemasan produk pangan kurangnya keberlanjutan merupakan kendala utama. Dengan demikian, pandangan inovasi sebagai meningkatkan produktivitas ialah untuk membuat terobosan- berbentuk produk, layanan yang terus mengikuti perkembangan zaman.

Sebagai sarana dalam meningkatkan produktivitas, inovasi dalam pandangan pengurus koperasi adalah parktik dari teori ke koporasian yang mereka dapatkan agar tidak hanya sekedar pengetahuan saja. Leonard \& Barton (1995) menyatakan bahwa inovasi adalah pengembangan melalui teknologi dalam bentuk produk baru. Dengan demikian, meningkatkan produktivitas merupakan konsekuensi dalam koperasi jika mana ingin tetap eksis dalam revolusi industri, hal tersebut sejalan dengan argumen Liao, Y., Loures, E. R., Deschamps, F., Brezinski, G., \& Venâncio (2017) bahwa revolusi industri keempat mendorong kemajuan ilmu pengetahuan dan teknologi, di mana Internet of Things berfungsi sebagai tulang punggung untuk sistem mesin pintar yang digunakan sebagai promotor untuk mengoptimalkan rantai produksi.

Selanjutnya berdasarkan hasil observasi di koperasi wilayah Kota Bandung, ditemukan bahwa peningkatan produktivitas mereka sudah cukup baik di tandai 
dengan hadirnya inovasi yang ada dalam koperasi. Tentu saja hal itu berdasar pada kemauan anggota koperasi dalam meningkatan produktivitas sebagai tanda mereka merupakan bagian dari koperasi. Hal tersebut sejalan dengan pendapat Fagerberg, Verspagen, \& Srholec (2010) bahwa dalam perspektif yang lebih luas ini, inovasi juga dalam hal produk, proses, atau cara baru atau lebih baik untuk melakukan sesuatu termasuk dalam kegiatan ekonomi.

Hasil penelitian juga menunjukan bahwa peningkatan produktivitas juga di dasarkan pada lokasi dimana koperasi itu ada. Misalnya berada di Kota Bandung, Kota Cimahi, Kabupaten Bandung dan Kabupaten Bandung Barat sesuai dengan konsep metropolitan Bandung Raya. Chalmers (2012) mengemukakan bahwa organisasi sosial dan berbasis komunitas semakin dipandang sebagai sumber inovasi sosial yang berharga. Maka dari itu, keberadaan koperasi di Bandung Raya menjadi kaidah dalam penegasan inovasi dalam berbagai sektor kehidupan manusia.

Makna inovasi dalam pandangan pengurus koperasi se-Bandung Raya kedua adalah sebagai kebutuhan pelanggan. Fleischmann (2019) menyatakan bahwa secara global terbukti bahwa kota-kota metropolitan dan negara-negara dengan indeks inovasi tinggi lebih mampu untuk bertransisi ke Ekonomi Sirkuler dengan menerapkan inovasi yang dipimpin desain. Dengan kata lain bahwa kinerja pengurus koperasi se Bandung Raya sangat dipengaruhi oleh inovasi pengurus koperasi se Bandung Raya yang di sesuaikan dengan kebutuhan pelanggan.

Berdasarkan hasil wawancara dengan narasumber ABP di koperasi wilayah Kota Cimahi mengenai makna inovasi pengurus koperasi se-Bandung Raya sebagai kebutuhan pelanggan. Di dapat hasil bahwa inovasi merupakan cara untuk memastikan daya saing dan kemajuan dalam bidang ekonomi. Hal tersebut sejalan dengan pendapat Pece, Simona, \& Salisteanu (2015) bahwa peningkatan investasi di bidang penelitian, penciptaan produk baru dan kemudahan akses investor ke pasar saham, pertama, akan memastikan perkembangan sektor swasta dan publik, dan kedua, akan meningkatkan kondisi kehidupan penduduk.

Hasil penelitian juga menunjukan bahwa inovasi pengurus koperasi se-Bandung Raya ialah juga cara dalam menjaga hubungan dengan pemerintah dalam hak kesejahteraan masyarakat. Koehler (2017) menyatakan bahwa tindakan untuk meningkatkan akses dalam jaringan inovasi meliputi informasi global, interaksi pribadi, pemeliharaan database, rekrutmen secara tepat dan memanfaatkan pengetahuan untuk mengidentifikasi tumpang tindih lokal dengan basis pengetahuan global.

Perkembangan kebutuhan pelanggan memang sejatinya memaksa inovasi, karena mau tidak mau agar tetap mendapat pelanggan, inovasi adalah hal yang harus di 
lakukan. Broughel \& Thierer (2019) menyatakan bahwa inovasi teknologi adalah pendorong fundamental pertumbuhan ekonomi dan kemajuan manusia. Maka inovasi yang diintegrasikan dengan kebutuhan pelanggan identik dengan inovasi.

Berdasarkan hasil observasi di koperasi wilayah Bandung Raya, mengenai makna inovasi pengurus koperasi se-Bandung Raya sebagai kebutuhan pelanggan sudah tergolong baik. Hal ini ditandai dengan adanya layanan atau jasa yang kekinian dan semakin memudahkan pelanggan. Vorley \& Nelles (2010) menyatakan bahwa transformasi basis ekonomi yang meluas telah menyaksikan kemerosotan ekonomi manufaktur tradisional dan kebangkitan ekonomi berbasis pengetahuan. Akibatnya, kebijakan industri berorientasi manufaktur konvensional telah menjadi 'berorientasi masa depan' terhadap tantangan ekonomi berbasis pengetahuan, dan semakin digantikan oleh kebijakan inovasi.

Makna inovasi dalam pandangan pengurus koperasi se-Bandung Raya ketiga adalah sebagai cara dalam meningkatkan kinerja. Telah disampaikan bahwa kinerja pengurus koperasi terdiri dari usaha koperasi, kepepengurusan, dua layanan anggota. Maka dari itu, pandangan inovasi sebagai cara dalam meningkatkan kinerja merupakan kabar yang yang bagu bagi dunia koperasi karena akan semakin meningkatkan kesadaran dalam berkoperasi. Grillo \& Landabaso (2011) menyatakan bahwa investasi publik dalam inovasi dianggap oleh pembuat kebijakan sebagai alat yang efektif untuk pembangunan daerah yang kurang berkembang. Maka dari itu, inovasi sebagai cara dalam meningkatkan kinerja merupakan Langkah dalam menangani ketidakseimbangan pembangunan regional, nasional dengan berpusat pada kekuatan pasar.

Dapat dikatakan bahwa era revolusi industri, teknologi masih dianggap sebagai kekuatan utama dalam hal perkmebnagan perekonomian didunia. Kemudian Hidayah, Sapriya, Darmawan, Malihah, \& Karliani (2020) mengemukakan bahwa kecerdawan warga negara merupakan akumulasi dari pengetahuan, sikap dan wataknya. Maka penguatan inovasi dalam meningkatkan kinerja merupakan implementasi dari pengetahuan dan habituasi dalam lingkungan koperasi.

Talbot (2016) menyatakan bahwa kegagalan sebagian besar ekonomi barat telah meningkatkan momok stagnasi sekuler. Berdasarkan hasil wawancara dengan narasumber PYI di koperasi wilayah Kabupaten Bandung mengenai makna inovasi pengurus koperasi se-Bandung Raya sebagai cara dalam meningkatkan kinerja. Di dapat bahwa kerangka organisasi koperasi idi Bandung Raya harus terus mengembangkan inovasi.

Narasumber MOK di koperasi wilayah Kabupaten Bandung Barat juga mengemukakan bahwa inovasi bisa terus meningkatkan dengan memanfaatkan tekhnologi informasi. Sejalan dengan hal tersebut, Bommersheim \& Chandra 
(2015) menyatakan bahwa proyek Inovasi melalui inklusi menawarkan platform kerja bersama untuk perusahaan rintisan dan usaha kecil dan menengah serta penyandang tunanetra atau tunanetra, untuk menciptakan hasil yang sama-sama menguntungkan bagi kedua komunitas. Dalam hal ini maka, inovasi dalam koperasi sebagai dalam meningkatkan kinerja juga selaras dengan kearifan lokal yang kian menjadi solusi di era global ini sebagaimana dinyatakan oleh Hidayah, Feriandi, \& Saputro (2019) bahwa kearifan lokal dapat menjadi penyemimbang di era revolusi industri.

Secara keseluruhan hasil wawancara mengenai pandangan pengurus koperasi seBandung Raya mengenai inovasi adalah sebagai berikut:

Tabel 2. Hasil wawancara mengenai pandangan pengurus koperasi se-Bandung Raya mengenai inovasi

\begin{tabular}{|c|c|c|}
\hline $\begin{array}{c}\text { Inovasi dalam koperasi } \\
\text { meningkatkan } \\
\text { produktivitas }\end{array}$ & $\begin{array}{c}\text { Inovasi dalam koperasi } \\
\text { sebagai kebutuhan } \\
\text { pelanggan }\end{array}$ & $\begin{array}{l}\text { Inovasi dalam koperasi } \\
\text { sebagai cara dalam } \\
\text { meningkatkan kinerja }\end{array}$ \\
\hline $\begin{array}{lr}\text { Makna inovasi dalam } \\
\text { meningkatkan } \\
\text { produktivitas } \\
\text { adanya integrasi antara } \\
\text { loyalitas } \\
\text { koperasi dan } & \text { pemhaman } \\
\text { mengenai } & \text { pentingnya } \\
\text { berkoperasi } & \end{array}$ & $\begin{array}{l}\text { Makna koperasi sebagai } \\
\text { kebutuhan pelanggan } \\
\text { adalah karena berbagai } \\
\text { sektor telah mengalami } \\
\text { perubahan signifikan } \\
\text { maka dalam praktik } \\
\text { pembangunan koperasi } \\
\text { harus menyesuaikan } \\
\text { dengan pasar }\end{array}$ & $\begin{array}{l}\text { Makna koperasi sebagai } \\
\text { cara dalam meningkatkan } \\
\text { kinerja adalah } \\
\text { bagaimana memberikan } \\
\text { solusi dengan menjalin } \\
\text { kemitraan yang } \\
\text { dihasilkan oleh anggota } \\
\text { hingga dapat diterima di } \\
\text { pasar }\end{array}$ \\
\hline
\end{tabular}

\section{KESIMPULAN}

Inovasi dalam pandangan pengurus koperasi se-Bandung Raya sebagai meningkatkan produktivitas. Sejalan dengan penelitian ini, makna inovasi dalam hal meningkatkan produktivitas ialah menjadi pengintegrasian antara loyalitas terhadap koperasi dan edukasi dalam berekonomi di koperasi se-Bandung Raya. Inovasi dalam pandangan pengurus koperasi se-Bandung Raya sebagai kebutuhan pelanggan ialah reaksi terhadap keberadaan revolusi industri. Selain itu, kebutuhan pelanggan ditujukan dalam mengetahui model penting dalam perkembangan koperasi se-Bandung Raya. Inovasi dalam pandangan pengurus koperasi se-Bandung Raya sebagai cara dalam meningkatkan kinerja. Dalam hal ini terdapat pembelajaran dalam hal inovasi di koperasi se-Bandung Raya. Koperasi menjadi wadah inovasi agar anggota koperasi memahami dan memaknai menganai inovasi. 
October , 2020

\section{REFERENSI}

Bello Dogarawa, A. (2005). The Role of Cooperative Societies in Economic Development. University Library of Munich, Germany, MPRA Paper. https://doi.org/10.2139/ssrn.1622149

Boer, H. (2001). Innovation, What Innovation? A Comparison between product, process and organizational innovation. International Journal of Technology Management - INT J TECHNOL MANAGE, 22, 83-107. https://doi.org/10.1504/IJTM.2001.002956

Bommersheim, E., \& Chandra, O. (2015). Innovation through inclusion: A pilot project. Local Economy, 30(5), 584-590. https://doi.org/10.1177/0269094215589562

Branch, M. C. (1995). Perencanaan kota komprehensif: pengantar \& penjelasan / Melville C. Branch; penerjemah Bambang Hari Wibisono. Yogyakarta: Gadjah Mada University Press.

Brat, E., Martínez, I., \& Ouchene, N. (2016). Innovation: Priorities and Practices in Cooperatives. https://doi.org/10.13140/RG.2.2.10606.10561

Broughel, J., \& Thierer, A. (2019). Technological Innovation and Economic Growth: A Brief Report on the Evidence. Arlington: Mercatus Center at George Mason University.

Chalmers, D. (2012). Social innovation: An exploration of the barriers faced by innovating organizations in the social economy. Local Economy, 28(1), 17-34. https://doi.org/10.1177/0269094212463677

Cleave, E., \& Arku, G. (2014). Competitiveness through cooperation: Analysis of spatial patterns and inter-jurisdictional collaboration in the place branding of Ontario communities, Canada. Local Economy, 29(4-5), 541-560. https://doi.org/10.1177/0269094214535716

Fagerberg, J., Verspagen, B., \& Srholec, M. (2010). Innovation and Economic Development. In Handbook of the Economics of Innovation (Vol. 2, hal. 833-872). https://doi.org/10.1016/S0169-7218(10)02004-6

Fleischmann, K. (2019). Design-led innovation and Circular Economy practices in regional Queensland. Local Economy, 34(4), 382-402. https://doi.org/10.1177/0269094219854679

Grillo, F., \& Landabaso, M. (2011). Merits, problems and paradoxes of regional innovation policies. Local Economy, 26(6-7), 544-561. https://doi.org/10.1177/0269094211417161 
Hidayah, Y., Feriandi, Y. A., \& Saputro, E. A. V. (2019). Transformasi Kearifan Lokal Jawa Dalam Pendidikan Karakter Sekolah Dasar. AULADUNA: Jurnal Pendidikan Dasar Islam, 6(1), 50-61.

Hidayah, Y., Sapriya, Darmawan, C., Malihah, E., \& Karliani, E. (2020). Promoting Civic Intelligence in Applied Science to Promote Interaction between Science: An Overview in the Perspective of Citizenship Education. Universal Journal of Educational Research, 8(8), 3782-3791. https://doi.org/10.13189/ujer.2020.080859.

Hosseini, S. J. F., McElwee, G., Soltani, S., \& Smith, D. J. (2012). The innovation performance of small rural enterprises and cooperatives in Tehran province, Iran. Local Economy, 27(2), 183-192. https://doi.org/10.1177/0269094211429909

Houston, D., Hillier, J., MacCallum, D., Steele, W., \& Byrne, J. (2017). Make kin, not cities! Multispecies entanglements and 'becoming-world' in planning theory. Planning Theory, 17(2), 190-212. https://doi.org/10.1177/1473095216688042

Koehler, K. A. (2017). Inducing phase transitions in local innovation networks: Implications for state economic development. Local Economy, 32(8), 854866. https://doi.org/10.1177/0269094217739370

Leonard, \& Barton, D. (1995). Wellspings of Knowledge: Building and Sustaining the Sourc- es of Innovation. Boston: Harvard Business School Press.

Liao, Y., Loures, E. R., Deschamps, F., Brezinski, G., \& Venâncio, A. (2017). The impact of the fourth industrial revolution: a cross-country/region comparison. Production. https://doi.org/10.1590/0103-6513.20180061

Maulana, M. I. (2016). Analisis Perkembangan Koperasi Di Indonesia Dibandingkan Dengan Negara-Negara Maju Dalam Perspektif Ekonomi Politik. Bogor: Departemen Ilmu Ekonomi Fakultas Ekonomi Dan Manajemen Institut Pertanian Bogor.

Miles, M.B. and Huberman, A. M. (1992). Analisis Data Kualitatif: Buku Sumber Tentang Metode-Metode Baru.Terjemahan Tjetjep Rohendi. Jakarta: Universitas Indonesia.

Mohajan, H. (2019). The First Industrial Revolution: Creation of a New Global Human Era, 5, 377-387.

Moleong, L. J. (2005). Metodologi Penelitian Kualitatif. Bandung: PT Remaja Rosda karya.

Nel, E., \& Stevenson, T. (2014). The catalysts of small town economic development in a free market economy: A case study of New Zealand. 
October , 2020

Local Economy, 29(4-5), 486-502. https://doi.org/10.1177/0269094214535022

Pece, A., Simona, O., \& Salisteanu, F. (2015). Innovation and Economic Growth: An Empirical Analysis for CEE Countries. Procedia Economics and Finance, 26, 461-467. https://doi.org/10.1016/S2212-5671(15)00874-6

Rahardjo, M. (2011). Koperasi Sukses Indonesia. Jurnal Maksipreneur: Manajemen, Koperasi, dan Entrepreneurship, 1, 1. https://doi.org/10.30588/jmp.v1i1.61

Raharja, S. J. (2013). Prospek dan Tantangan Pengembangan Koperasi di Indonesia Pasca Undang-Undang Nomor 17 Tahun 2012 tentang Perkoperasian. Jurnal Administrasi Bisnis, 9(2), 117-127.

Rysz, K., \& Mazurek-Matuszewska, K. (2015). Contemporary foundations of the theory of urban development - case study smart, slow and compact city theory. Environmental \& Socio-economic Studies, 3. https://doi.org/10.1515/environ-2015-0072

Sitepu, C. F., \& Hasyim. (2018). Perkembangan Ekonomi Koperasi Di Indonesia. Niagawan, 7(2).

Skerratt, S., \& Steiner, A. (2013). Working with communities-of-place: Complexities of empowerment. Local Economy, 28(3), 320-338. https://doi.org/10.1177/0269094212474241

Talbot, S. (2016). Creating a smart rural economy through smart specialisation: The microsphere model. Local Economy, 31(8), 892-919. https://doi.org/10.1177/0269094216678601

Tim WJP-MDM. (2013). Konsep Awal Pengembangan Metropolitan Bandung Raya. Diambil dari http://metropolitan.jabarprov.go.id/sources/download/paper/6f79c-06konsep-awal-pengembangan-metropolitan-bandung-raya_juni2013_a22.pdf

Vorley, T., \& Nelles, J. (2010). Innovation Policy as Industrial Policy: Some Lessons from Hamburg's Regional Innovation System. Local Economy, 25(8), 631-649. https://doi.org/10.1080/02690942.2010.533422

Zain, M. A. (2014). Politik Hukum Koperasi Di Indonesia (Tinjauan Yuridis Historis Pengaturan Perkoperasian Di Indonesia). Yogyakarta. 